\title{
Analyzing inconsistent cases in management fsQCA studies: A methodological manifesto
}

\author{
Lakshmi Balachandran Nair, Università della Svizzera italiana \\ Michael Gibbert, Università della Svizzera italiana
}

Submitted: February 2015

Revised: June 2015

Accepted: September 2015

The authors thank Prof. Charles Ragin, Prof. Peer Fiss and Prof. Rodney Lacey for their helpful comments. Project grant \#100018_134523 from Swiss National Science Foundation funded this research. Please send correspondence to Lakshmi Balachandran Nair, Facoltà di scienze della comunicazione, Università della Svizzera italiana, Lugano, Switzerland, E-mail addresses: lakshmi.balachandran.nair@usi.ch, and Michael Gibbert, Facoltà di scienze della comunicazione, Università della Svizzera italiana, Lugano, Switzerland, E-mail addresses: michael.gibbert@usi.ch. 


\begin{abstract}
Cases inconsistent with theoretical expectations are by default indicators for a lack of theorydata fit, and as such are prime candidates for theory building. However, the conventional tendency is to ignore inconsistent cases in management research. The current article focuses on the theory-building prowess of inconsistent or deviant cases which turn up during an fsQCA study. The study looks at some of the key tenets of QCA: A cross-tabulation of cause and effect can demonstrate superior explanatory completeness only if one can account for all cases (be they deviant or not). To improve the neat theory-data fit characteristic of QCA, the paper proposes two new strategies for analyzing inconsistent cases of necessity and sufficiency in fuzzy set QCA studies and discusses their contributions to methodological sophistication.
\end{abstract}

Keywords: QCA, Inconsistent Cases, Theory Building, Multi Method Research 


\section{Introduction}

An important arena for using multi-method research is in the analysis of inconsistent cases or outliers. The inconsistent cases can occur both in quantitative survey-based research designs as well as in qualitative case study research, and are often clear indicators for a lack of theory-data fit, and as such are prime candidates for theory building (see Katz, 1988; Sullivan, 2011). A research design allowing for outlier analysis would therefore help re-establish the cases' significance in the theorizing process (Locke, Golden-Biddle, \& Feldman, 2008). In Management, despite their theory-building competence, researchers tend to ignore, and sweep the outliers under the proverbial carpet of model fit (Aguinis, Gottfredson, \& Joo, 2013; Gibbert, Nair, \& Weiss, 2014). Typically, outliers are small in number, calling for a qualitative, and often comparative, analysis of the cases that deviate from the main body of observations (Kendall $\&$ Wolf, 1949; Pearce, 2002).

Fundamentally, Qualitative Comparative Analysis (QCA) is herein a particularly promising method. One of QCA's hallmarks, the cross-tabulation of cause and effect, can demonstrate superior explanatory completeness only if one accounts for all cases (be they deviant or not). To improve the neat theory-data fit characteristic of QCA, the current study proposes two new strategies for analyzing inconsistent cases of necessity and sufficiency in fuzzy set QCA studies. Specifically, the paper conceptually details two post-QCA research strategies, namely "Comparative Outlier Analysis" (COA), and discusses their relative merits in terms of building theory more rigorously. The paper deliberates examples for both strategies, from prior studies on and applying QCA. With QCA progressively acknowledged as a viable research method in Management and Organization Research (Greckhamer, Misangyi, Elms, \& Lacey, 2008; Fiss, 2007; Fiss, 2011), a research design integrating QCA and COA will be not only timely, but also 
very relevant for theoretical advancement in Management research as well as methodological progress in QCA.

\section{Case oriented strategies in QCA}

Prior research addresses the importance of case-oriented strategies for supplementing QCA studies. Case study research serves as a post-QCA step (Schneider \& Rohlfing, 2013) providing help in ascertaining the specific cases (Ragin, 2000), establishing and calibrating the relevant conditions included in the analysis (Berg-Schlosser, De Meur, Rihoux, \& Ragin, 2009), and addressing contradictory configurations and outcomes (Ragin, 1987). Case oriented strategies are also applicable simultaneously during the course of QCA studies for refining causal arguments and addressing "empirical refutation of initial arguments" (Ragin \& Schneider, 2012).

Finally, case studies are also suitable for identifying post-QCA deviant cases. Process tracing a deviant case is helpful in further improving the theory and the QCA model (Schneider \& Rohlfing, 2013). The present paper moves beyond process tracing of a single deviant case and offers further steps for comparatively analyzing a series of post-QCA deviant cases. The focus here is predominantly on fsQCA cases, so as to present a clear application scenario for the application of the COA technique. Clearly, the underlying strategy is also suitable for analyzing csQCA deviant cases. But for expository purposes and space constraints, the current study does not discuss csQCA deviant case scenarios.

\section{Why analyze the inconsistent cases in QCA?}

The QCA technique bases itself on Mill's “canons," especially the Method of Difference and the Method of Agreement. The Method of Difference states that if an instance where a phenomenon occurs and an instance where a phenomenon does not occur have every 
circumstance in common except one, which occurs in the former instance and not in the latter, the particular circumstance is the cause, or an indispensable part of the cause, of the phenomenon. The Method of Agreement instead deals with similarities in observed cases. The logic states that if two or more instances of a phenomenon show only one circumstance in common, that particular circumstance then constitutes the cause or effect of the given phenomenon (Mill, 1875). Both methods have to do with establishing common causal relationships by eliminating all other possible alternative explanations (Berg-Schlosser et al., 2009). Nonetheless, rigid positivistic assumptions of cause and effect relationships may not always work so neatly in the case of social sciences, where a multitude of causes and conditions intersect in time and space to produce a particular outcome.

In fact, non-conforming cases may even be more important than typical cases as they can be of great help in the understanding of causal complexity. Unlike in other research methods, where researchers neglect deviant cases or outliers as unavoidable nuisance, QCA "tends to give explanations without dismissing exceptions or outliers" (Berg-Schlosser et al., 2009). The tendency occurs because most studies undertaking a regression or similar methods focus on averaging out the large numbers of cases under study. QCA, meanwhile, takes into consideration even a combination of conditions that explains only a single case (Berg-Schlosser et al., 2009).

However, even in QCA researchers tend to reject cases inconsistent with expectations (Rihoux \& Ragin, 2009). The rejection significantly reduces the concerned study's explanatory power (i.e. internal validity). The rationale behind the above rife tendency is the belief that the exceptional circumstances are somehow idiosyncratic, unlikely to be repeated elsewhere, and are therefore of little interest theoretically. From the perspective of the philosophy of science, clearly one would be unwise to take the same stance. In addition, one of the hallmarks of QCA is that a 
cross-tabulation of cause and effect can demonstrate superior explanatory completeness (Western, 2001) only if there is the possibility of accounting for all cases, deviant or not (Ragin, 1987). The present study hones in on the very essence of QCA by providing a road map for analyzing the deviant cases identified during a QCA study in terms of two concrete strategies.

Naturally, since deviant cases are assessable only in relation to an explicitly framed theoretical model, the relative deviance of a case would also change when altering the general model (Seawright \& Gerring, 2008). In a similar vein, what constitutes a QCA deviant case is very much in the eye of the beholder, and so depends upon the specifications made by the researcher regarding just which causal conditions apply, and which individual cases to include or exclude from the initial study. Without any reflection and systematic application to the available data, there would be a serious impairment to both the internal as well as the external validity of the emergent theory.

\section{COA- How to analyze outliers in a QCA?}

The current section details the methodological sophistication of the two COA designs and their potential in terms of providing stronger (i.e. more internally and externally valid) theory. Outlier analysis techniques have their basis in Yin's (2003) "Replication Logic.” Replication Logic is a tool for enhancing the possibility of making causal claims and comparing cases with regard to plausible alternative explanations, but which differ with regard to the independent variables of interest purported to cause the observed effects (Gibbert, Nair, \& Ruigrok, 2013). Two basic approaches exist; Literal Replication and Theoretical Replication (Yin, 2003).

"Literal Replication" involves comparing cases that are similar to each other, are from the same end of the theoretical spectrum, and could predict similar results (Yin, 2003; Gibbert et al., 
2013). The Literal Replication procedure is similar to the Replication Deviant Case Method (Gibbert et al., 2014) or the Most similar system design- Method of agreement (Faure, 1994), both of which involve a comparison of cases which are very similar to each other in terms of the phenomena of interest. The cases are similar not only in terms of the causal condition, but also in terms of the outcome. Outlier Literal Replication (OLR), the first COA strategy, has its basis herein.

"Theoretical Replication," on the other hand, involves the comparison of cases from different ends of a theoretical model and the prediction of dissimilar results, but due to foreseeable reasons (Yin, 2003; Gibbert et al., 2013). The strategy is comparable to the "Full Range Deviant Case Method" (Gibbert et al., 2014) in qualitative and quantitative studies. As per the Method of Difference and Method of Agreement, two possible types of OTR could exist (Faure, 1994). The first design is the "most similar system" (i.e., method of difference). In the design, the comparison is between cases which show the same causal condition as typical cases, but with a different (though theoretically predictable) outcome. The underlying notion is that, the more comparable the cases are with respect to the causal conditions, the greater the feasibility to segregate factors which cause the disparity in the outcome. The second type of OTR is the Most different system (Method of Agreement). The design considers cases which are similar in the outcome shown, but differ from each other in terms of the causal conditions. Comparing cases which differ with regard to the causal conditions supposedly causing the observed effects (Gibbert et al., 2013) helps in exploring plausible alternative explanations, the development of new causal claims and, ultimately, building stronger theory (i.e. theory which is both internally and externally valid). 
For emphasis, one can recall that the outlier analysis techniques would differ in csQCA and fsQCA, and also with respect to the necessity and sufficiency of conditions. Here, the focus is specifically on the fsQCA inconsistent cases. As fsQCA handles varying degrees of membership in the causal condition and outcome (Ragin, 2008), a wide range of typical and outlying cases are available for COA, making fsQCA particularly attractive and instructive as an application context.

\section{Analysis of multiple outliers in fsQCA}

Analyzing and comparing multiple outliers is of great importance in theory building because doing so would help establish the internal validity and external validity of the modified proposition (Lijphart, 1971). COA permits the researcher to do within-case and between-case comparisons that would help determine whether the deviance noticed is just a one-off case, or is observable across several cases (Eisenhardt \& Graebner, 2007). Unlike in prior studies on outlier analysis techniques, the general purpose of COA is not to find the necessary and sufficient conditions for an outcome and explain how each term relates to the phenomenon of interest exclusively (Berg-Schlosser et al., 2009; George \& Bennett, 2005). Rather, the focus is on ascertaining the plausibility of causal relationships between variables (Mill, 1875; Cook, Campbell, \& Day, 1979), expanding the scope of the theory in hand, or even laying the foundations for a new theory. For the same reason the focus here is not solely on positive outcomes, but on different combinations of memberships and outcomes. The first step here would also be conducting the analysis of a single deviant case. The specification of the causal recipe herein could in turn function as a hypothesis about other cases (Ragin \& Schneider, 2012). The OLR and OTR would follow consecutively. Tables 1 and 2 show all the COA techniques in fsQCA. 
Tables 1 and 2 here.

\subsection{COA in fsQCA cases of Necessity}

In necessity, the instances of outcome constitute a subset of the instances of the causal condition (Rihoux \& Ragin, 2009). The subset relation signals the connection between the causal conditions and the outcome. Accordingly, instances inconsistent with the subset relation are not typical cases. Based on the presence and absence of an outcome in the presence and absence of a necessary condition, cases can be classified.

In fsQCA of Necessity, suitable cases for COA would be the most and least likely typical cases (Beach \& Pederson, 2013) and deviant cases of consistency, subdivided into cases of degree and kind (Schneider \& Rohlfing, 2013). Figure 1 shows the cases in fsQCA of Necessity, which could be suitable candidates for COA. For comparative analysis, the cases where the necessary condition is absent but the outcome is present, that is, the deviant cases of consistency (kind), can be considered first. The cases' occurrence hints at the possibility that another condition or alternative explanation could have been present for the outcome in question to happen. By applying COA, the researcher could suggest a modification of the theory in hand that is externally valid beyond the case in hand. The second possibility involves deviant cases of consistency (degree). Deviant cases (degree) are qualitatively quite similar to typical cases, except that they do not confirm to the statement of necessity (Schneider \& Rohlfing, 2013).

Typical cases are cases which have membership in both the necessary term and outcome. The typical cases can again be subdivided into "most-likely" and "least-likely" cases depending on their respective positions within the zone (Mahoney \& Goertz, 2004) of typical cases. Mostlikely cases have high values on both the necessary term and outcome, while least-likely cases 
have low values. The remaining fsQCA Necessity case-types are not anomalous by reference to the general model of causal relations (Maggetti, Radelli, \& Gilardi, 2012), and hence are irrelevant for COA.

Figure 1 here.

\section{1.a. OLR in fsQCA cases of Necessity.}

The generalizability and theory building potential of analyzing a single deviant case is relatively limited (relative to analyzing several cases in a replication mode). If the purpose of the research is greater generalizability and theory enhancement, there is the possibility of a comparison with other similar outcome deviant cases. The researcher embarks on within-case, and between-case comparisons to understand and establish the applicability of the causal factors across a broader spectrum of cases (whether consistent or inconsistent with theoretical expectations). In the case of deviant cases of consistency occurring while testing necessity, one can carry out an OLR, a.k.a. comparison of the deviant cases of consistency with other similar deviant cases. The focus is on the causal conditions that the positive cases have in common, while there is an elimination of conditions that have nothing in common as they have no explanatory power here (Blatter \& Haverland, 2012).

Analysis of fsQCA deviant cases of necessity would require a comparison of deviant cases of consistency (degree and kind). The deviant cases of consistency (kind) are situated in the top left-hand corner of the plot. Literal replication of deviant cases of consistency (kind) with other deviant cases of consistency from the same location, is the most sophisticated OLR technique. Another possible category, deviant cases of consistency (degree), is in the top right-hand corner 
of the plot. Comparing the deviant cases of consistency (degree), with each other would be another interesting OLR technique.

\section{1.b. OTR in fsQCA cases of Necessity.}

An even more sophisticated analysis technique compares cases with different outcomes with an eye on reconciling any differences theoretically. OTR suggests the researcher deliberately chooses outcomes that are on the extreme ends of an emerging, theoretical continuum (e.g. high/low values on the causal recipe). When compared with analysis of a single deviant case or OLR , the technique is particularly advanced methodologically, as well as being more promising theoretically. Since there is an examination is of cases from extreme ends of a theoretical spectrum, the theoretical purchase on the empirical data (internal validity) increases, and the scope of the theory becomes broader (enhancing the external validity).

Recall that the focus here is on cases with similar necessary conditions, but different results; a comparison of typical cases (most and least likely) with the deviant cases of consistency (degree). Here, the outlying cases are quite similar to the typical cases in terms of the outcome. As discussed earlier, this OTR design is quite similar to the Most similar system (Method of Difference). A comparison would thus lead to a refined hypothesis, the identification of further necessary conditions, or clarification of the scope conditions (Blatter \& Haverland, 2012). To sum up, OTR goes beyond refuting an existing theory and moves towards formulating a potentially new theory. OTR thus represents a kind of recipe for creating a theoretical contribution.

The second type of OTR of fsQCA cases of Necessity involves the deviant cases of consistency (kind) with typical cases. Here the deviant cases have a causal mechanism different 
from typical cases, and yet they show the outcome. Comparing the typical cases (most and least likely) with the deviant cases of consistency (kind) might point to new causal conditions or alternate mechanisms in play which could have caused the occurrence of the outcome. The OTR design under discussion here is similar to the Most different system (Method of Agreement).

\subsection{COA in $f$ SQCA cases of Sufficiency}

FsQCA Sufficiency provides a myriad of cases (Schneider \& Rohlfing, 2013) for COA (see Figure 2). Deviant cases for consistency contradict the statement of sufficiency by being a member of the QCA solution, but not being a member of the outcome. The typical cases are the ones which lie on the upper right-hand side of the spectrum (above the diagonal as they are consistent with the statement of sufficiency). The cases in the lower half of the diagonal are inconsistent with the statement of sufficiency and are thus deviant. As in the case of the fsQCA cases of Necessity, one can also subdivide the cases into deviant cases of consistency (degree and kind). The former occupy the location below the diagonal adjacent to the typical cases, whereas the latter occupy the lower right-hand side of the theoretical prediction.

Deviant cases for coverage, on the other hand, are the ones that are not members of the QCA solution, but still show the outcomes. Such deviant cases occupy the upper left-hand side of the spectrum. They have no membership score in the sufficent term, a high membership score in the outcome, and are consistent with the statement of sufficiency. Deviant cases for coverage do not exactly contradict the statement of sufficiency, as the sufficient cause is not always necessary for the outcome to occur. However, analyzing such deviant cases would still be fruitful, as the analysis could lead to the discovery of an overlooked causal recipe or condition which could have been the cause. There is a list of the different COA techniques in the cases of sufficiency in 
the subsequent sections. As in the case of fsQCA Necessity, the remaining cases are irrelevant for COA.

Figure 2 here.

\section{2.a. OLR in fsQCA cases of Sufficiency.}

In cases of sufficiency, one can perform an OLR (Most similar system - Method of Agreement) by comparing the deviant cases of consistency with other similar deviant cases. Here, one first process traces the cases which are members of the QCA solution, but are not members of the outcome, and then compares the cases with each other. As in the instance of fsQCA Necessity cases, the technique would involve comparing deviant cases of consistency (degree) which are similar to typical cases, with other deviant cases of consistency (degree). An alternative (and even more promising) possibility is to compare deviant cases of consistency (kind) with a high membership score on the sufficient term and a low membership score on the outcome, with other deviant cases of consistency (kind). An analysis of the latter could help identify the reasons why the supposedly sufficient causal condition/ recipe does not produce the expected outcome.

Yet, another possibility would be to compare the different deviant cases for coverage with each other. Here, there is a comparison of the cases which are not members of the QCA solution, but which still display the outcome. The comparison is useful when the focus of the analysis is on identifying the reasons behind the high membership in the outcome despite having no membership in the sufficient term. Something to be cautious about is that the deviance can be due to any reason other than the sufficient condition, which could make the comparison difficult. The initial process-tracing step would be able to curb the difficulty. 


\section{2.b. OTR in fsQCA cases of Sufficiency.}

OTR in cases of Sufficiency can be in two forms. The first comparison could be between typical cases and deviant cases for coverage, where the outcome is present in both instances, with the sufficient term absent in the deviant cases (Most different system - Method of Agreement). The second comparison would be between typical cases and deviant cases of consistency, where both cases would be members of the QCA solution of sufficiency, with the deviant cases not members of the outcome, or being a member but also showing inconsistency with the set theoretic relationship of sufficiency (Most similar system - Method of Difference).

OTR of fsQCA Sufficiency cases thus provide an extensive range of possible comparisons. The "most likely" cases are compared with the deviant cases of consistency (degree and kind) and the deviant cases for coverage, providing three possible ways of comparison. Likewise, the least likely cases are also compared with the three types of deviant cases, providing yet another three opportunities for theory enhancement.

\section{Concrete examples of analysis of deviant cases using $\mathrm{COA}$}

So far, the present study has illustrated the methodological sophistication of the two COA methods in terms of their underscoring the key strength of QCA, with only the occasional hint at the theoretical gains associated with the proposed methodological innovation. To illustrate the theoretical gains more graphically, Table 3 includes some cases identified as deviant cases during the course of studies using a configurational approach. As can be seen from the examples, not all authors undertake a further analysis of identified deviant cases. In principle, there is no problem if the authors intend to focus only on the phenomenon which interested them initially. However, if they are keen on understanding the reasons behind the observed deviance, and 
eventually in expanding the theory building potential of their study beyond the scope of the initial study, COA would indeed be a blueprint for moving forward.

Table 3 here.

\section{Discussion}

\subsection{COA and Process Tracing}

Process tracing a post-QCA deviant case is valuable in serving as a test for a theory in hand, finding out new properties of the identified deviant case, and is also the first step in every COA study. However, with a single case, generating a theory with much depth would be difficult and its theoretical grounding would not be credible enough (Eisenhardt, 1989). Process tracing a deviant case can establish the causal mechanism existing between causal conditions and outcomes, thus advancing the internal validity of a study. COA, on the other hand, replicates the findings on other similar (OLR) and dissimilar (OTR) cases to see how the causal conditions exist in a range of cases, thus ensuring the present study's external validity. Together, the two methods further the rigor of the study.

\subsection{COA and contributions to $Q C A$}

COA, like QCA, has a fundamental anchor in Mill's Method of Difference and Method of Agreement. For the same reason, COA techniques are quite complementary to QCA. At the same time, the causality and complexity of social causation and the heterogeneity of cases lead to the impossibility of a QCA model covering all cases or providing precise, focused explanations to all cases (Glaesser \& Cooper, 2011). COA focuses on analyzing cases which a particular QCA 
model cannot cover, thus contributing to theory enhancement. QCA provides configurations which comprise skeletal types of cases (Glaesser \& Cooper, 2011), as they exist in the social world, thus eliminating the need for further theoretical sampling. Thus, COA and QCA are mutually supplementary. An OLR design compares similar deviant cases with one another, thus helping to figure out the common circumstance which leads to the phenomenon of interest. OTR design (Most similar system- Method of Difference) looks into cases which notify the omitted conditions not incorporated into the initial QCA model, and hence cause the expected outcome not to occur despite the presence of other conditions. In contrast, the Most different systemMethod of Agreement OTR considers cases which point to alternative conditions which lead the deviant cases to show the same outcome as typical cases despite the absence of relevant conditions.

\subsection{COA for achieving generality, accuracy, and complexity}

According to Thorngate's (1976) “postulate of commensurate complexity,” a researcher always has to make compromises between the three meta-theoretical virtues of generality, accuracy, and objectivity in research. Conversely, Woodside (2010) puts forth the "postulate of disproportionate achievement," whereby tradeoffs between the three objectives are not mandatory. Through property space analysis, the possibility arises of arriving at theoretically possible combinations of conditions for achieving all three objectives (Woodside, 2010). Fuzzy set social sciences (like fsQCA) have high generality and accuracy, but low coverage. Multiple case studies (as in COA) meanwhile have high accuracy and coverage, but low generality. A combination of QCA and COA would make achieving all three objectives possible. 


\section{Limitations}

One of the main observations of the present study is there is not always a comparative analysis of post-QCA inconsistent cases in Management, thus presenting a difficulty in demonstrating the various replication designs the study is suggesting. Even some of the examples presented are not demonstrative enough as not all of them actually carry out an outlier analysis per se. However, the current paper includes the best instances from the study sample and the literature, which could illustrate the idea.

COA as a technique is not without its flaws either. OLR, where one compares outlying cases with each other, may be prone to an external validity problem as there is a between-case comparison of similar cases only. OTR does not face the problem. However, conducting an OTR could be taxing in terms of the time, effort, and resources involved. A good way to avoid any squandering of resources would be to first make sure the inconsistent cases under study are not due to any error, but due to some phenomenon which may be "interesting" to the researcher (Aguinis et al., 2013). Prior knowledge about the cases and a sound theoretical base could help in addressing the problems to some extent. As QCA is a method already requiring familiarity with the relevant theories, the relevant literature, and sensitivity to the cases in hand, obtaining indepth knowledge on the cases for COA would be feasible.

\section{Conclusion}

The COA technique is perfectly complementary and supplementary at the same time to the QCA approach. QCA studies normally require the number of cases to be more than eight. COA, in contrast, takes into account cases which are very small-N. In a case where incorporating inconsistent cases into a QCA study is impossible due to their inadequate numbers, COA is a 
very good alternative. Furthermore, the technique perfectly fits in with QCA, as both methods implicate "thick data," making the individual QCA "units of observation" very suitable for undergoing COA.

Today a lot of work is taking place out with regard to analyzing outliers identified during qualitative and quantitative studies. Deviant cases are gaining more and more importance in Management research, as is the configurational approach. Yet, the current paper is the first one to encourage a comparative analysis of inconsistent cases in QCA using a qualitative method. The present study is also the first one to advocate a comparison of deviant cases with other deviant and typical cases in QCA. By combining QCA and COA together, the current study contributes to management research methodology. 


\section{References}

Aguinis, H., Gottfredson, R.K., \& Joo, H. (2013). Best-practice recommendations for defining, identifying, and handling outliers. Organizational Research Methods, 16(2), 270-301.

Beach, D., \& Pedersen, R.B. (2013). Process-tracing methods: Foundations and guidelines. Michigan: University of Michigan Press.

Berg-Schlosser, D., De Meur, G., Rihoux, B., \& Ragin, C.C. (2009). Qualitative Comparative Analysis (QCA) as an approach. Configurational Comparative Methods, 1-18.

Blatter, J., \& Haverland, M. (2012). Designing case studies. Explanatory approaches to small-n research. Basingstoke: Palgrave Macmillan.

Cook, T.D., Campbell, D.T., \& Day, A. (1979). Quasi-experimentation: Design \& analysis issues for field settings. Boston: Houghton Mifflin.

Cooper, B., \& Glaesser, J. (2012, March). Qualitative work and the testing and development of theory: lessons from a study combining cross-case and within-case analysis via Ragin's QCA. In Forum Qualitative Sozialforschung/Forum: Qualitative Social Research (Vol. 13, No. 2).

Eisenhardt, K.M., \& Graebner, M.E. (2007). Theory building from cases: Opportunities and challenges. Academy of Management Journal, 50(1), 25-32.

Eisenhardt, K.M. (1989). Building theories from case study research. The Academy of Management Review, 14(4), 532-550.

Faure, A. M. (1994). Some methodological problems in comparative politics. Journal of Theoretical Politics, 6(3), 307-322. 
Fischer, J., Kaiser, A., \& Rohlfing, I. (2006). The push and pull of ministerial resignations in Germany, 1969-2005. West European Politics, 29(4), 709-735.

Fiss, P.C. (2007). A Set-theoretic Approach to Organizational Configurations. Academy of Management Review, 32,1180-1198.

Fiss, P.C. (2011). Building Better Causal Theories: A Fuzzy Set Approach to Typologies in Organization Research. Academy of Management Journal, 54, 393-420.

George, A.L., \& Bennett, A. (2005). Case studies and theory development in the social sciences. Cambridge: MIT Press.

Gibbert, M., Nair, L.B., \& Ruigrok, W. (2013, June). Boosting internal and external validity in case study research: A review (1996-2006). Paper presented at European Academy of Management Conference, Istanbul, Turkey.

Gibbert, M., Nair, L.B., \& Weiss, M. (2014, August). “Oops, I've got an outlier in my datawhat now?" Using the Deviant Case Method for theory building. Paper presented at the $74^{\text {th }}$ Academy of Management Annual Meeting, Philadelphia, USA.

Glaesser, J., \& Cooper, B. (2011). Selectivity and flexibility in the German secondary school system: A configurational analysis of recent data from the German socio-economic panel. European Sociological Review, 27(5), 570-585.

Greckhamer, T., Misangyi, V.F., Elms, H., \& Lacey, R. (2008). Using Qualitative Comparative Analysis in strategic management research: An examination of combinations of industry, corporate, and business-unit effects. Organizational Research Methods, 11(4), 695-726. 
Katz, J. (1988). Seductions of crime. New York: Basic Books.

Kendall, P.L., \& Wolf, K.M. (1949). The analysis of deviant cases in communications research. In P. F. Lazarsfeld \& F. W. Stanton (Eds.), Communications research (pp. 152-179). New York: Harper.

Lijphart, A. (1971). Comparative politics and the comparative method. The American Political Science Review, 65(3), 682-693.

Locke, K., Golden-Biddle, K., \& Feldman, M.S. (2008). Perspective-Making Doubt Generative: Rethinking the Role of Doubt in the Research Process. Organization Science, 19(6), 907-918.

Maggetti, M., Radaelli, C. M., \& Gilardi, F. (2012). Designing research in the social sciences. Sage.

Mahoney, J., \& Goertz, G. (2004). The possibility principle: Choosing negative cases in comparative research. American political science review, 98(4), 653-669.

Mill, J. (1875). A system of logic, ratiocinative and inductive: Being a connected view of the principles of evidence and the methods of scientific investigation. London: Longmans, Green, Reader and Dyer.

Pearce, L.D. (2002). Integrating survey and ethnographic methods for systematic anomalous case analysis. Sociological Methodology, 32(1), 103-132.

Ragin, C.C. (1987). The comparative method: Moving beyond qualitative and quantitative strategies. Berkley: University of California Press.

Ragin, C.C. (2000). Fuzzy-set social science. Chicago: University of Chicago Press. 
Ragin, C.C. (2008). Redesigning social inquiry: Fuzzy sets and beyond. Chicago: University of Chicago Press.

Ragin, C.C., \& Schneider, G. A. (2012). Comparative Political Analysis: Six Case-Oriented Strategies. The Wiley-Blackwell Companion to Political Sociology, 78-91.

Rihoux, B., \& Ragin, C.C. (Eds.). (2009). Configurational comparative methods: Qualitative comparative analysis (QCA) and related techniques. Thousand Oaks, CA: Sage Publications.

Schneider, C.Q., \& Rohlfing, I. (2013). Combining QCA and process tracing in set-theoretic multi-method research. Sociological Methods \& Research, 42(4), 559-597.

Seawright, J., \& Gerring, J. (2008). Case selection techniques in case study research a menu of qualitative and quantitative options. Political Research Quarterly, 61(2), 294-308.

Sullivan, C.J. (2011). The utility of the deviant case in the development of criminological theory. Criminology, 49(3), 905-920.

Thorngate, W. (1976). "In General" vs. "It Depends": Some Comments of the Gergen-Schlenker Debate. Personality and Social Psychology Bulletin, 2(4), 404-410.

Western, B. (2001). Bayesian thinking about macrosociology, American Journal of Sociology 107(2), 353-378.

Woodside, A. G. (2010). Bridging the chasm between survey and case study research: Research methods for achieving generalization, accuracy, and complexity. Industrial Marketing Management, 39(1), 64-75. 
Woodside, A.G., \& Baxter, R. (2013). Achieving accuracy, generalization-to-contexts, and complexity in theories of business-to-business decision processes. Industrial Marketing Management, 42(3), 382-393.

Yin, R.K. (2003). Case study research: Design and methods (3rd ed.). Thousand Oaks, CA: Sage Publications. 


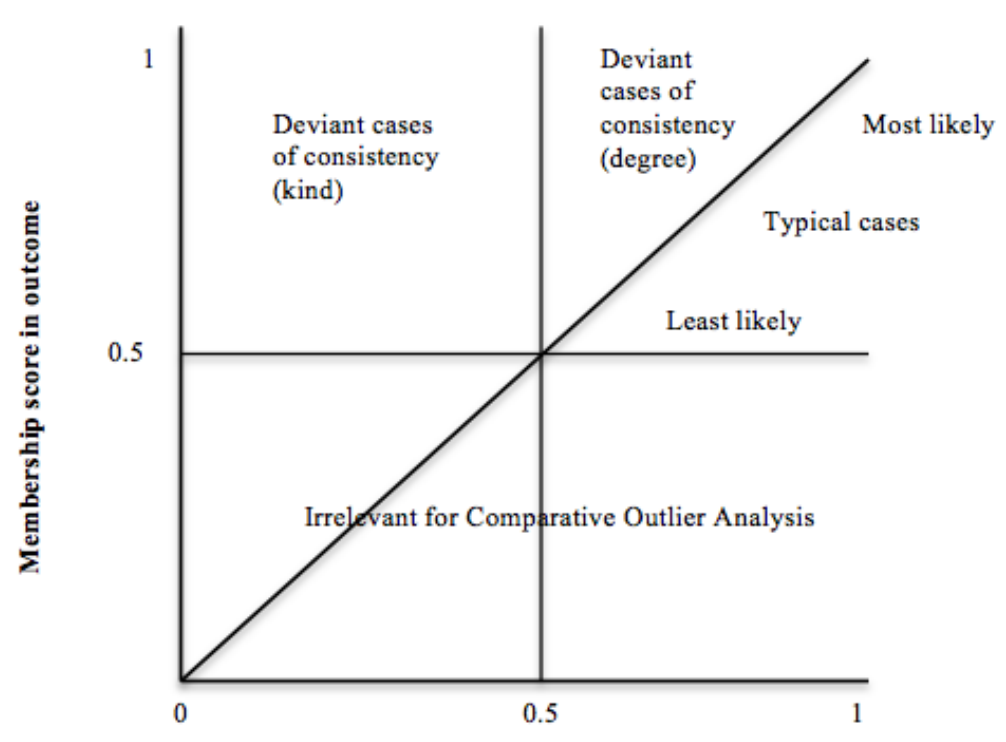

Membership score in necessary term

Figure 1. Type of cases in fsQCA (Necessity). Adapted from Schneider \& Rohlfing, 2013.

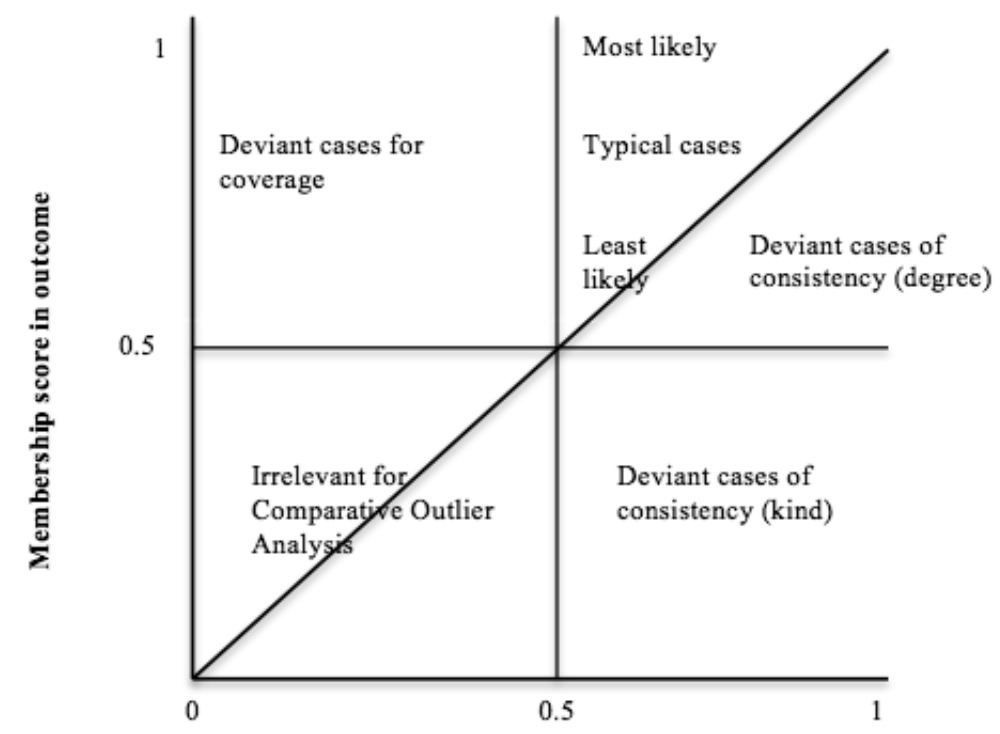

Membership score in sufficient term

Figure 2. Type of cases in fsQCA (Sufficiency). Adapted from Schneider \& Rohlfing, 2013. 


\section{Comparative Outlier Analysis: fsQCA (Necessity)}

\begin{tabular}{|c|c|c|c|}
\hline $\begin{array}{l}\text { Outlier } \\
\text { Literal } \\
\text { Replication }\end{array}$ & \multicolumn{2}{|c|}{$\begin{array}{l}\text { 1. Deviant cases of consistency } \\
\text { (degree) and deviant cases of } \\
\text { consistency (degree) } \\
\text { 2. Deviant cases of consistency (kind) } \\
\text { and deviant cases of consistency } \\
\text { (kind) }\end{array}$} & \\
\hline $\begin{array}{l}\text { Outlier } \\
\text { Theoretical } \\
\text { Replication }\end{array}$ & \multicolumn{2}{|c|}{$\begin{array}{l}\text { Most similar system (Method of } \\
\text { Difference) } \\
\text { Similar causal condition }(X), \text { different } \\
\text { outcome }(Y)\end{array}$} & $\begin{array}{l}\text { Most different system (Method of } \\
\text { Agreement) } \\
\text { Different causal condition }(X) \text {, similar } \\
\text { outcome }(Y) \\
\qquad \begin{array}{l}\text { 1. Typical cases and deviant cases of } \\
\text { consistency (kind) }\end{array}\end{array}$ \\
\hline \multicolumn{3}{|l|}{$\begin{array}{l}\text { Irrelevant for } \\
\text { Comparative } \\
\text { Outlier } \\
\text { Analysis }\end{array}$} & $\begin{array}{l}\text { Most different system (Method of } \\
\text { Difference) } \\
\text { Different causal condition }(X) \text {, different } \\
\text { outcome }(Y)\end{array}$ \\
\hline \multicolumn{2}{|l|}{ Typical cases } & \multirow{3}{*}{\multicolumn{2}{|c|}{$\begin{array}{l}=\text { high } \mathrm{X} \text {, high } \mathrm{Y} \text {, consistent with statement } \\
\text { of necessity } \\
=\text { high } \mathrm{X} \text {, high } \mathrm{Y} \text {, inconsistent with } \\
\text { statement of necessity } \\
=\text { low } \mathrm{X} \text {, high } \mathrm{Y} \text {, inconsistent with statement } \\
\text { of necessity }\end{array}$}} \\
\hline \multicolumn{2}{|c|}{ Deviant cases of consistency (degree) } & & \\
\hline \multicolumn{2}{|c|}{ Deviant cases of consistency (kind) } & & \\
\hline
\end{tabular}

Table 1. COA in fsQCA Necessity. 
Comparative Outlier Analysis: fsQCA (Suffieiency)

\begin{tabular}{|c|c|c|c|}
\hline $\begin{array}{l}\text { Outlier } \\
\text { Literal } \\
\text { Replication }\end{array}$ & \multicolumn{3}{|c|}{$\begin{array}{l}\text { 1. Deviant cases of consistency } \\
\text { (degree) and deviant cases of } \\
\text { consistency (degree) } \\
\text { 2. Deviant cases of consistency (kind) } \\
\text { and deviant cases of consistency } \\
\text { (kind) } \\
\text { 3. Deviant cases for coverage and } \\
\text { deviant cases for coverage }\end{array}$} \\
\hline $\begin{array}{l}\text { Outlier } \\
\text { Theoretical } \\
\text { Replication }\end{array}$ & \multicolumn{2}{|c|}{$\begin{array}{l}\text { Most similar system (Method of } \\
\text { Difference) } \\
\text { Similar causal condition }(X), \text { different } \\
\text { outcome }(Y)\end{array}$} & $\begin{array}{l}\text { Most different system (Method of } \\
\text { Agreement) } \\
\text { Different causal condition }(X) \text {, similar } \\
\text { outcome }(Y) \\
\quad \begin{array}{l}\text { 1. Typical cases and deviant cases for } \\
\text { coverage }\end{array}\end{array}$ \\
\hline \multicolumn{3}{|l|}{$\begin{array}{l}\text { Irrelevant for } \\
\text { Comparative } \\
\text { Outlier } \\
\text { Analysis }\end{array}$} & $\begin{array}{l}\text { Most different system (Method of } \\
\text { Difference) } \\
\text { Different causal condition }(X) \text {, different } \\
\text { outcome }(Y)\end{array}$ \\
\hline $\begin{array}{l}\text { Typical } \\
\text { Devian }\end{array}$ & $\begin{array}{l}\text { ases of consistency (degree) } \\
\text { ases of consistency (kind) }\end{array}$ & $\begin{array}{l}=\text { high } X \text {, } \\
\text { of necess } \\
=\text { high X, } \\
\text { statemen } \\
=\text { high } X \\
\text { of necess } \\
=\text { low X, } \\
\text { necessity }\end{array}$ & $\begin{array}{l}\text { igh } \mathrm{Y}, \text { consistent with statement } \\
\mathrm{y} \\
\text { high } \mathrm{Y} \text {, inconsistent with } \\
\text { of necessity } \\
\text { ow } \mathrm{Y} \text {, inconsistent with statement } \\
\mathrm{y} \\
\text { igh Y, consistent with statement of }\end{array}$ \\
\hline
\end{tabular}

Table 2. COA in fsQCA Sufficiency. 


\begin{tabular}{|c|c|c|c|c|c|}
\hline Article & Brief summary & Causal conditions & $\begin{array}{l}\text { Outcome as in } \\
\text { typical cases }\end{array}$ & Deviant cases & COA technique involved \\
\hline $\begin{array}{l}\text { "The push and pull } \\
\text { of ministerial } \\
\text { resignations in } \\
\text { Germany, 1969- } \\
\text { 2005" by Fischer, } \\
\text { Kaiser, and } \\
\text { Rohlfing (2006) as } \\
\text { mentioned in the } \\
\text { paper by Rihoux } \\
\text { and Ragin (2009). }\end{array}$ & $\begin{array}{l}\text { The authors study the } \\
\text { reasons leading to } \\
\text { ministerial resignations. } \\
\text { They argue that ministers } \\
\text { are forced to resign when } \\
\text { the political costs of a } \\
\text { minister staying in office } \\
\text { is higher than the } \\
\text { benefits of keeping the } \\
\text { status quo. They test this } \\
\text { by doing a QCA study } \\
\text { involving resignation } \\
\text { events in Germany (1969 } \\
\text { to 2005). }\end{array}$ & $\begin{array}{l}\text { "date of offence," "criminal } \\
\text { relevance," "minister's } \\
\text { position," "federal } \\
\text { chancellor's position," } \\
\text { "position of the minister's } \\
\text { party," "position of the } \\
\text { coalition partner," "position } \\
\text { of the parliamentary } \\
\text { opposition," "position of the } \\
\text { media and public," "political } \\
\text { or extra political kind of } \\
\text { resignation issue," and } \\
\text { "relationship of offence to } \\
\text { office." (Sufficient } \\
\text { conditions) }\end{array}$ & $\begin{array}{l}\text { "ministerial } \\
\text { resignation" }\end{array}$ & $\begin{array}{l}\text { "non- } \\
\text { resignation" } \\
\text { (Two cases) }\end{array}$ & $\begin{array}{l}\text { Outlier Literal Replication } \\
\text { (Most similar system- Method } \\
\text { of Agreement) By comparing } \\
\text { the two similar deviant cases } \\
\text { with each other, the authors } \\
\text { identify a potential omitted } \\
\text { variable "the intensity of a crisis } \\
\text { in terms of aggravating events } \\
\text { within a period of time" (Rihoux } \\
\text { and Ragin, 2009) }\end{array}$ \\
\hline $\begin{array}{l}\text { "Achieving } \\
\text { accuracy, } \\
\text { generalization-to- } \\
\text { contexts, and } \\
\text { complexity in } \\
\text { theories of business- } \\
\text { to-business decision } \\
\text { processes" by } \\
\text { Woodside and } \\
\text { Baxter (2013). }\end{array}$ & $\begin{array}{l}\text { The authors elaborate on } \\
\text { a business-to-business } \\
\text { process study of } \\
\text { marketing and } \\
\text { purchasing industrial } \\
\text { chemicals conducted by } \\
\text { Woodisde and Wilson } \\
\text { (2000). The study looks } \\
\text { upon the multiple } \\
\text { contingency paths of the } \\
\text { ways in which the buyers } \\
\text { and marketers think, and } \\
\text { act before making a } \\
\text { buying decision. }\end{array}$ & $\begin{array}{l}\text { "customer has large anmual } \\
\text { purchase requirements," } \\
\text { "customer willingness to } \\
\text { single source requirements," } \\
\text { and "customer } \\
\text { objective/aggressiveness with } \\
\text { respect to price." (Sufficient } \\
\text { conditions) }\end{array}$ & $\begin{array}{l}\text { "customer } \\
\text { share of } \\
\text { business } \\
\text { awarded to firm } \\
X^{\prime \prime}\end{array}$ & $\begin{array}{l}\text { "Case } 11 \text { ", has a } \\
\text { high } \\
\text { membership in } \\
\text { the causal recipe } \\
\text { and yet a low } \\
\text { membership in } \\
\text { the outcome. } \\
\text { (One case) }\end{array}$ & $\begin{array}{l}\text { Outlier Theoretical Replication } \\
\text { (Most similar system- Method } \\
\text { of Difference) The authors } \\
\text { conduct further analysis of this } \\
\text { outlier to find out that this } \\
\text { customer (Case } 11 \text { ) filed } \\
\text { complaints with his } \\
\text { manufacturer-sales manager and } \\
\text { tried to renegotiate prices during } \\
\text { the annual contract several times. } \\
\text { Clearly, case } 11 \text { is an unsatisfied } \\
\text { customer. Probing for reasons } \\
\text { behind his dissatisfaction may } \\
\text { require further follow-up } \\
\text { analysis. }\end{array}$ \\
\hline $\begin{array}{l}\text { "Qualitative work } \\
\text { and the testing and } \\
\text { development of } \\
\text { theory: Lessons } \\
\text { from a study } \\
\text { combining cross- } \\
\text { case and within- } \\
\text { case analysis via } \\
\text { Ragin's QCA" by } \\
\text { Cooper and } \\
\text { Glaesser (2012). }\end{array}$ & $\begin{array}{l}\text { The authors use the } \\
\text { SOEP (representative } \\
\text { panel study) from } \\
\text { Germany to ascertain the } \\
\text { types of school young } \\
\text { people attend at the age } \\
\text { of } 17 \text { (Gymnasium: } \\
\text { offers the qualification } \\
\text { 'Abitur' for university } \\
\text { entry, Realschule, and } \\
\text { Hauptschule). }\end{array}$ & $\begin{array}{l}\text { "having at least one parent } \\
\text { with the highest school } \\
\text { qualification 'Abitur'," } \\
\text { "having at least one parent in } \\
\text { the service class," "whether } \\
\text { the student is male or } \\
\text { female," and "whether the } \\
\text { student had a } \\
\text { recommendation for } \\
\text { Gymnasium." (The } \\
\text { recommendation for } \\
\text { Gymnasium is a quasi- } \\
\text { necessary condition for the } \\
\text { outcome.) }\end{array}$ & $\begin{array}{l}\text { "the student } \\
\text { was at } \\
\text { gymnasium by } \\
\text { age 17" }\end{array}$ & $\begin{array}{l}\text { "the student was } \\
\text { at gymnasium } \\
\text { by age } 17 " \\
\text { despite having } \\
\text { no } \\
\text { recommendation } \\
\text { to attend the } \\
\text { gymnasium. } \\
\text { (Six cases) }\end{array}$ & $\begin{array}{l}\text { Outlier Theoretical Replication } \\
\text { (Most different system- } \\
\text { Method of Agreement) Further } \\
\text { analysis of two of these deviant } \\
\text { cases pointed out that when it } \\
\text { comes to the outcome; some } \\
\text { factors like a good knowledge of } \\
\text { the system, family environment, } \\
\text { level of cognitive ability etc. } \\
\text { might be able to substitute for } \\
\text { the quasi-necessary condition of } \\
\text { gymnasium recommendation. }\end{array}$ \\
\hline
\end{tabular}

Table 3. Examples of COA from the prior literature. 